\title{
A STUDY OF UTILIZATION AND DETERMINANTS OF FAMILY WELFARE SERVICES IN RURAL JAMMU
}

\author{
Bhavna Sahni ${ }^{1}$, Shalini Sobti², Vridhee Sharma³, D.S. Jamwal ${ }^{4}$
}

\section{HOW TO CITE THIS ARTICLE:}

Bhavna Sahni, Shalini Sobti, Vridhee Sharma, DS Jamwal. "A study of utilization and determinants of family welfare services in rural Jammu". Journal of Evolution of Medical and Dental Sciences 2013; Vol. 2, Issue 42, October 21; Page: 8006-8012.

ABSTRACT: BACKGROUND: India was the first country in the world to launch National Family Planning Programme in 1952. Ironically, even after 60 years of its initiation, the couple protection rate is far from what is desirable although it has quadrupled from 10.4 percent in 1971 to 44 percent in 1999. The present study was therefore taken up to evaluate the utilization of FW Services at grass root level and to identify the determinants of the same. OBJECTIVES: To assess the utilization and determinants of family welfare services in rural Jammu. SETTING: Rural. DESIGN: Cross- sectional. METHODS: 10 sub-centres areas, out of the existing 25 in R S Pura Block of Jammu, were randomly selected. To assess the utilization of FW services, the house-hold survey registers maintained at the selected sub centres and updated during RCH survey 2007 were thoroughly scrutinized. This was followed by home-visits of $10 \%$ of the couples enlisted in those records for studying the determinants of utilization and reasons for non utilization of these services. STATISTICAL ANALYSIS: was done using proportions, percentages and Chi Square test. RESULTS: Utilization of FW services was observed among $61.91 \%$ of the eligible couples. On further statistical analysis, this utilization was found to be significantly associated with the age of the wife and husband and the number of living children. CONCLUSIONS: There is still scope for improving the utilization of Family Welfare Services and the predictors identified in the present study for utilization/ non-utilization of the same can be thoroughly scrutinized for planning targeted interventions.

KEY WORDS: Utilization, family welfare, eligible couple, contraceptive, sub-centre, RCH survey, socio-economic status.

INTRODUCTION: In the census figures of 1951, the Planners recognized the potential threat posed by population explosion and the need to take steps to avert it. Hence, India became the first country in the world to formulate a National Family Planning Programme in 1952. After 1952, sharp declines in death rates were, however, not accompanied by a similar drop in birth rates. The National Health Policy, 1983 stated that replacement levels of total fertility rate (TFR) should be achieved by the year 2000 .Henceforth, health care of women and children and provision of contraceptive services has been the focus of India's health services. The Centrally Sponsored and 100\% centrally funded Family Welfare Programme provides infrastructure, manpower and consumables needed for improving health status of women and children and to meet all the felt need s for fertility regulation 1 .

The 1994 International Conference on Population and Development (ICPD) provided a forum for countries to commit to making efforts to decrease fertility rates by focusing on women's reproductive health, particularly the need for family planning programs ${ }^{2}$. Six years later, the UN established the Millennium Development Goals in 2000 which are intimately linked with family planning, especially MDG 5 which calls for the reduction of the maternal mortality ratio by threequarters and for the achievement of universal access to r eproductive health by 2015 3,4. 
The National Population Policy, 2000 (NPP 2000) affirms the commitment of government towards voluntary and informed choice and consent of citizens while availing of reproductive health care services, and continuation of the target free approach in administering family planning services. The NPP 2000 provides a policy framework for advancing goals and prioritizing strategies during the next decade, to meet the reproductive and child health needs of the people of India, and to achieve net replacement levels (TFR) by 2010.

Keeping this background in mind, the present study was taken up to evaluate the utilization of FW Services at the peripheral-most point in the three tier system of health care and to identify predictors of the same.

METHODOLOGY: A study to elicit the utilization of Family Welfare services was carried out in RS Pura block which is the rural field practice area of Government Medical College, Jammu. The block is located in the South-West of Jammu City, at a distance of 22 kilometers from GMC, Jammu. There is 1 community health centre, 5 primary health centres, 3 allopathic dispensaries, 25 health sub-centres and 209 villages with an estimated population of 1,80,560 5 .

Out of the existing 25 sub-centres, 10 sub-centres areas were randomly selected for the purpose of study. The house-hold survey registers maintained and updated at sub-centre level during RCH survey 2007 were thoroughly scrutinized for the purpose of the study. The data contained in these records was critically analyzed to find out the extent of utilization of FW services and its association with age of wife and husband and the number of living children. This was followed by home-visits of a sub-sample (10\%) of the enlisted couples selected from sub centre records by systematic random sampling. During home visits, utilization of Family Welfare Services was studied with respect to the female partner's literacy level and socio-economic status of the family (using Modified Uday Pareek Scale).

The help of anganwadi worker/ ASHA/ MPHW (F) etc. was taken for carrying out the homevisits.

Couples who were using any temporary / permanent method of family welfare were classified as having 'utilized' family welfare services while those couples who were not using any method of contraception were classified as 'not having utilized' the family welfare services and reasons for non-utilization were also ascertained.

All the data thus obtained for the ten health sub-centres areas was compiled and tabulated. The analysis was done using the standard appropriate statistical techniques which included proportions, percentages and Chi Square test (with Yates correction wherever applicable) using Epiinfo 6.04 version.

Eligibility criteria: although 'Eligible couples' have been defined as those with wife in the age-group of 15-45 years but in the present study Couples with wife in the age group of 18-45 years have been included.

Exclusion criteria: Couples with wife less than 18 years and husbands less than 21 years of age in accordance with The Prohibition of Child Marriage Act - 20066.

Period (with month \& year) \& place of study: January to December 2009, RS Pura Block in Jammu, J \& K. 


\section{OBSERVATIONS:}

\begin{tabular}{|c|c|c|c|}
\hline Name of Sub-centre & Population & No. of villages & $\begin{array}{c}\text { No. of eligible couples as } \\
\text { per RCH Survey } 2007\end{array}$ \\
\hline Mamka & 3500 & 5 & 437 \\
\hline Choala & 5460 & 5 & 581 \\
\hline Jinder Melu & 5013 & 5 & 224 \\
\hline Dablehar & 7700 & 5 & 1067 \\
\hline Seer & 3122 & 5 & 565 \\
\hline Baspur & 4250 & 7 & 773 \\
\hline Kirpind & 6391 & 5 & 1054 \\
\hline Narhi & 5213 & 5 & 259 \\
\hline Chak M Yaar & 3252 & 5 & 575 \\
\hline Langotian & 4700 & 7 & 734 \\
\hline Total & 48601 & 54 & 6269 \\
\hline
\end{tabular}

\begin{tabular}{|c|c|c|}
\hline I) ELIGIBLE COUPLES USING ANY METHOD & NO. OF ELIGIBLE COUPLES & PERCENTAGE \\
\hline A) PERMANENT METHODS & & \\
\hline Female Sterilization & 2345 & 37.41 \\
\hline Male Sterilization & 25 & 0.40 \\
\hline B) TEMPORARY METHODS & 123 & 1.96 \\
\hline Oral pills & 116 & 1.85 \\
\hline Intra Uterine Devices & 1272 & 20.29 \\
\hline Condoms & 2388 & 38.09 \\
\hline II) ELIGIBLE COUPLES NOT USING ANY METHOD & 6269 & 100 \\
\hline \multicolumn{2}{|c|}{ TOTAL ELIGIBLE COUPLES } \\
\hline
\end{tabular}

\begin{tabular}{|c|c|c|c|}
\hline Age- Group of Wife & $\begin{array}{c}\text { Using any method } \\
(\%)\end{array}$ & $\begin{array}{c}\text { Not using any method } \\
(\%)\end{array}$ & Total Eligible Couples \\
\hline 18-25 years & 377 (29.87\%) & $885(70.13 \%)$ & 1262 \\
\hline 26-35 years & $1910(65.73 \%)$ & $996(34.27 \%)$ & 2906 \\
\hline 36-45 years & $1594(75.87 \%)$ & $507(24.13 \%)$ & 2101 \\
\hline Total & $3881(61.91 \%)$ & $2388(38.09 \%)$ & 6269 \\
\hline
\end{tabular}

$\chi^{2}=740.09 ;$ df $2 ; \mathrm{p}$ value $<0.01 ;$ Highly Significant 


\begin{tabular}{|c|c|c|c|}
\hline $\begin{array}{l}\text { Age-Group } \\
\text { of Husband }\end{array}$ & $\begin{array}{l}\text { Eligible Couples using } \\
\text { any method (\%) }\end{array}$ & $\begin{array}{c}\text { Eligible Couples not } \\
\text { using any method (\%) }\end{array}$ & $\begin{array}{l}\text { Total Eligible } \\
\text { Couples }\end{array}$ \\
\hline 21-25 years & $47(16.32 \%)$ & $241(83.68 \%)$ & 288 \\
\hline $26-35$ years & $1244(50.61 \%)$ & $1214(49.39 \%)$ & 2458 \\
\hline $36-45$ years & $1945(73.87 \%)$ & $688(26.13 \%)$ & 2633 \\
\hline 46-55 years & 637 (73.05\%) & 235 (26.95\%) & 872 \\
\hline 56 years \& above & $8(44.44 \%)$ & $10(55.56 \%)$ & 18 \\
\hline Total & $3881(61.91 \%)$ & $2388(38.09 \%)$ & 6269 \\
\hline
\end{tabular}

$\chi^{2}=594.86 ;$ df 4; p value <0.01; Highly Significant.

\begin{tabular}{|c|c|c|c|}
\hline Contraceptive method used & $\leq 2$ children $(\%)$ & $\geq 3$ children $(\%)$ & Total \\
\hline Tubectomy/vasectomy & 682(28.78) & $1688(71.22)$ & 2370 \\
\hline Intrauterine device & $81(69.83)$ & $35(30.17)$ & 116 \\
\hline Oral pills & $93(75.61)$ & $30(24.39)$ & 123 \\
\hline Condoms & $928(72.96)$ & $344(27.04)$ & 1272 \\
\hline None & $1894(79.31)$ & $494(20.69)$ & 2388 \\
\hline Total & $3678(58.67)$ & $2591(41.33)$ & 6269 \\
\hline
\end{tabular}

$\chi^{2}=1420.66 ;$ df 4; p value 0.000001; Highly Significant.

\begin{tabular}{|c|c|c|c|}
\hline \multirow{2}{*}{ Female Education } & \multicolumn{2}{|c|}{ Utilization of Family Planning Services } & \multirow{2}{*}{ Total females } \\
\hline & Utilized (\%) & Not utilized (\%) & \\
\hline Up to $10^{\text {th }}$ & $159(42.29)$ & $217(57.71)$ & 376 \\
\hline 10th- Inter & $167(83.08)$ & $34(16.92)$ & 201 \\
\hline Degree \& above & $50(100.00)$ & $0(0.00)$ & 50 \\
\hline Total & 376 (59.97) & $251(40.03)$ & 627 \\
\hline
\end{tabular}

$\chi^{2}=2.54 ;$ df 2; p value >0.05; Not Significant.

\begin{tabular}{|c|c|c|c|}
\hline \multirow{2}{*}{ Socio-Economic Status } & \multicolumn{2}{|c|}{ Utilization of Family Planning Services } & \multirow{2}{*}{ Total females } \\
\hline & Utilized (\%) & Not utilized (\%) & \\
\hline BPL, Lower, Lower middle & $67(28.63)$ & $167(71.37)$ & 234 \\
\hline Middle class & $234(75.73)$ & 75 (24.27) & 309 \\
\hline Higher middle, Upper class & $75(89.29)$ & $9(10.71)$ & 84 \\
\hline Total & 376 (59.97) & $251(40.03)$ & 627 \\
\hline
\end{tabular}

$\chi^{2}=5.54 ;$ df 2; p value >0.05; Not Significant. 
Contraceptive use among the eligible couples was found to be $61.91 \%$. Among the couples using spacing methods, majority had $\leq 2$ children while among the 2730 couples using permanent methods, $71.22 \%$ had $\geq 3$ children. On statistical analysis of the Sub centre records, the association of age of the wife and husband, \& number of living children, with utilization of FW services was found to be highly significant.

On conducting house to house visits 627 (10\%) of the couples were contacted and but no significant association of female partners' literacy level \& socio-economic status of the family with the utilization of these services was seen.

Among the females who reported non-utilization of Family Welfare services, it was observed that the main reasons were lack of awareness of the importance of family welfare services, nonavailability of health staff and irregular availability of contraceptives at the health care facilities, fear of side-effects, inconvenience, desire for more children and unsuitable timings of government health care facilities for working mothers belonging to poor families.

DISCUSSION: The records of eligible couples were reviewed and all the relevant information was analyzed from the house-hold registers maintained at sub-centre level and updated during RCH Survey 2007. It was observed that out of 6269 eligible couples enlisted in the ten sub-centre areas, $37.41 \%$ of females and $0.40 \%$ of males had undergone sterilization as against national figures of $37.3 \%$ and $1 \%$ female and male sterilizations respectively (NFHS-3, 2005-06) ${ }^{7}$. These observations prove that the participation of men in the family welfare programme is dismal as regards to permanent methods. Among the temporary methods, condoms were the most commonly used (20.29\%) followed by oral pills (1.96\%) and IUD's (1.85\%). Thus, $61.91 \%$ of the eligible couples were using some method and $38.09 \%$ were not using any method of contraception. Similar results have been reported by Singh and Arora ${ }^{8}$ with $38 \%$ and $0.4 \%$ females and males who had und ergone tubectomy and vasectomy respectively, followed by usage of $2 \%$ oral pills and $2 \%$ IUD's. An ICMR task force study 9 also reported similar findings with $34.2 \%$ eligible couples using permanent methods of contraception. Other similar studies 10,11,12,13 also reported that permanent methods were used by $41.3 \%, 27 \%, 38.6 \%$ and $18 \%$ of eligible couples respectively. However, various other studies $14,15,16,17,18,19$ reported that $40.65,28 \%, 28 \%, 35 \%, 45.83 \%$ and $75 \%$ eligible couples respectively were using some method of contraception.

In the present study it was observed that usage of family welfare methods increased with increasing age of women and the association was found to be highly significant at p value $<0.01$. This finding is in accordance with the observations made in other studies 10, 12, 18 .

When the results for the utilization of family welfare methods among the eligible couples were analyzed according to number of living children, it was observed that $71.22 \%$ of the couples who had undergone sterilization had 3 or more children and majority of the couples who were using temporary methods or who were not using any method had 2 or less than 2 children. A study carried out in rural North India ${ }^{8}$ reported that $92 \%$ of eligible couples using permanent methods had 3 or more children, and most of the condom or oral pill users had 2 or less than 2 children. The present results are in accordance with the observations of the study on fertility pattern and family planning practices carried out in a rural area in Dakshina Kannada 16 which reported that $71 \%$ of women with three or more children were acceptors of permanent methods. Another study ${ }^{14}$ reported that contraceptive users had an average of 3.9 living children while non-users had 1.9 living children. 
This is in contrast to another study ${ }^{20}$ which reported that high parity was associated with non use of contraceptives.

The findings of this study indicate a shift in the choice of the preferred contraceptive by eligible couples even in rural areas, as permanent methods were being used by most of the couples with 3 or more living children and temporary methods by most of the couples with 2 or less living children.

It was felt necessary in the current study to enquire the reasons for non-utilization of FW services among the sub-sample of registered eligible couples who were contacted by house-to-house visits. The major reasons cited in the present study were lack of awareness of the importance of family welfare services, non-availability of health staff and irregular availability of contraceptives at the health care facilities, fear of side-effects, inconvenience, desire for more children and unsuitable timings of government health care facilities for working mothers belonging to poor families. Other similar studies $14,21,22,10,23,5,9,17,11$ also reported desire for more children, side effects of contraceptives, failure rates as major reasons for partial and non-utilization of family welfare services.

From the study, it has been concluded that there is still scope for improving the utilization of Family Welfare Services and the predictors identified in the present study for utilization/ nonutilization of the same can be thoroughly scrutinized for planning targeted interventions.

\section{REFERENCES:}

1. http://planningcommission.nic.in/plans/planrel/fiveyr/9th/vol2/v2c3-5.html

2. Gakidou E, Vayena E. Use of Modern Contraception by the poor is falling behind. PLoS Med. 2007; 4(2):e31.

3. Singh S, Darroch J, Ashford L, Vlassoff M. "Adding It Up: The Costs and Ben efits of Investing in Family Planning and Maternal and Newborn Health". Guttmacher Institute and UNFPA. 2010.

4. Campbell M, Cleland J, Ezeh A, Prata N. Return of the population growth factor. Science. 2007; 315:1501-2.

5. 5. Census 2001: Office of the Registrar General \& Census Commissioner, India, New Delhi.

6. Govt. Of India (2010) Annual Report 2009-10, Ministry of Women and Child Development, New Delhi.

7. National Family Health Survey (NFHS 3), India, 2005-06, International Institute for Population Sciences, Mumbai, India.

8. Singh A, Arora AK. The Changing profile of pregnant women and quality of antenatal care in rural north India. Indian J Community Med. 2007; 32 (2): 135-136.

9. Chandhiok N, Dhillon BS, Kambo I, Saxena NC. Contraceptive knowledge, practices and utilization of services in rural areas of India (an ICMR task force study). Indian Journal of Medical Science, 2003; 57: 303-310.

10. Kumar R, Singh MM, Kaur M. Dynamics of contraceptive use in a rural community of Haryana. Indian J Med Sci. 1999; 53: 201-211.

11. Bhasin SK, Pant M, Mehta M, Kumar S. Prevalence of usage of different contraceptive methods in East Delhi- A cross sectional study. Indian J Community Med. 2005; 30(2): 53-55. 
12. Kansal A, Chandra R, Kandpal SD, Negi KS. Epidemiological correlates of contraceptive prevalence in rural population of Dehradun district. Indian J Community Med. 2005; 30(2): 60-62.

13. Agarwal S, Bharti BM. Reproductive health in urban slums. J Obstet Gynaecol India. 2006; 56(3): 255- 257.

14. Rajaratnam T, Deshpande RV. Factors Inhibiting the Use of Reversible Contraceptive Methods in Rural South India. Stud Fam Plann. 1994; 25 (2): 111-121.

15. Das R, Amir A, Nath P. Utilization and Coverage of Services by Women of Jawan Block in Aligarh. Indian J Community Med. 2001; 26(2):94.

16. Mohanan P, Kamath A, Sajjan BS. Fertility Pattern and Family Planning Practices in a Rural Area in Dakshina Kannada. Indian J Community Med. 2003; 28(1):15.

17. Puri A, Garg S, Mehra M. Assessment of Unmet need for Contraception in an urban slum of Delhi. Indian J Community Med. 2004, 29(3): 139-140.

18. Bhattacharya SK, Ram R, Goswami DN, Gupta UD, Bhattacharya K, Ray S. Study of unmet need for family planning among women of reproductive age group attending immunization clinic in a medical college of Kolkata. Indian J Community Med. 2006; 31(2): 73-75.

19. Gupta M, Thakur J, Kumar R. Reproductive and Child Health Inequities in Chandigarh Union Territory of India. J Urban Health. 2008 March; 85(2): 291-299.

20. Mondal A. Non-Use, Unsatisfactory Use and Satisfactory Use of Contraceptives (A Rural Study). J Obstet Gynaecol. 1992; 678-682.

21. Kartikeyan S, Chaturvedi RM. Family Planning: Views of Female Non-Acceptors in Rural India. J Postgrad Med. 1995; 41(2): 37-39.

22. Visaria L. Unmet Need for Family Planning in Gujarat: A Qualitative Exploration. Econ Polit Wkly. 1997; 32(2): 29-36.

23. Ram R, Ghosh MN, Bhattacharya S. Study of unmet need for family planning among married women of reproductive age attending immunization clinic in a Medical College of Calcutta. Indian J Community Med. 2000; 25(1):22-25.

\section{AUTHORS:}

1. Bhavna Sahni

2. Shalini Sobti

3. Vridhee Sharma

4. D.S. Jamwal

\section{PARTICULARS OF CONTRIBUTORS:}

1. Lecturer, Department of Comm unity Medicine, ASCOMS, Jammu.

2. Lecturer, Departm ent of Community Medicine, ASCOMS, Jammu.

3. Lecturer, Department of Community Medicine, ASCOMS, Jammu.
4. Professor \& Head, Department of Community Medicine, Chintpurni Medical College.

\section{NAME ADDRESS EMAIL ID OF THE CORRESPONDING AUTHOR:}

Dr. Bhavna Sahni,

473, Nitco Lane,

Talab Tillo, Jammu, J \& K.

Email - bhavnasahni@gmail.com

Date of Submission: 26/09/2013.

Date of Peer Review: 27/09/2013.

Date of Acceptance: 08/10/2013.

Date of Publishing: 15/10/2013 